Çukurova Üniversitesi Mühendislik Mimarlık Fakültesi Dergisi, 34(3), ss. 247-253, Eylül 2019

\title{
Karayolu Temel/Alttemel Zemin Uygulamaları: Çorum/Merzifon Ayrımı-Mecitözü-Amasya/Turhal Ayrımı
}

\author{
Özen KILIÇ ${ }^{1}$, Eren ÖZDAMAR ${ }^{* 1}$ \\ ${ }^{1}$ Çukurova Üniversitesi, Mühendislik Fakültesi, Maden Mühendisliği Bölümü, Adana
}

Geliş tarihi: $16.09 .2019 \quad$ Kabul tarihi: 30.09 .2019

$\ddot{O} z$

Bu çalışmada, 2017 yılında yapımına başlanmış (Çorum-Merzifon) Ayrımı -Mecitözü- (Amasya-Turhal) Ayrımı 0+000-61+841,27 km arası bölünmüş yol yapımı işi bünyesinde, Karayolu temel/alttemel zemin uygulamaları araştırılmıştır. Karayolları Teknik Şartnamesi (KTŞ) gözetilerek, yol yapımında kullanılmakta olan materyaller ile çalışılmıştır. İlk olarak $\mathrm{Km}$ : $23+600$ üzerinde zemin analizleri yapılmıştır. Sonuçlara göre temel/alttemel katmanları oluşturulmuştur. Sağlamlık kontrolü için yapılan kum konisi deneyleri sonucunda, Km: 11+500-23+600 arasında \%98,4-100 sıkışma ile dolgu-terasman kotunda, Km: 17+280-19+600 arasında \%98,0-99,8 sıkışma ile Plent Mix Alttemel (PMAT) kotunda, Km: 17+28019+600 arasında \%100 sıkışma ile Plent Mix Temel (PMT) kotunda, Karayolları Teknik Şartnamesi’ne (KTŞ) göre elde edilen veriler neticesinde çalışmalar tamamlanarak, optimum zemin stabilizasyonu sağlanmıştır.

Anahtar Kelimeler: Mecitözü yolu, Zemin, Karayolu, Temel/alttemel, Üstyapı

\section{Highway Foundation/Subbase Soil Applications: Çorum/Merzifon Road Junction- Mecitözü-Amasya/Turhal Road Junction}

\begin{abstract}
In this study, construction started in 2017 (Çorum-Merzifon) Road junction -Mecitözü- (Amasya-Turhal) Road junction Road base/subbase soil applications were investigated within the scope of divided road construction work between $0+000-61+841,27 \mathrm{~km}$. Considering the Technical Specifications of Highways (HTS), the materials used in road construction were studied. Firstly, ground analyzes were performed on $\mathrm{Km}: 23+600$. According to the results, the base/sub-base layers were formed. As a result of sand cone tests for strength control, 98.4-100\% compaction between Km: 11+500-23+600 at filling-terrage elevation, Km: $17+280-19+600$ between 98,0-99,8\% at the Plent Mix Subbase (PMAT) elevation, Km: 17+280-19+600 Plent Mix Basic (PMT) with 100\% compaction, according to the data obtained (according to HTS), optimum gorund stabilization was achieved.
\end{abstract}

Keywords: Mecitözü road, Soil, Highway, Foundation/subbase, Superstructure

"Sorumlu yazar (Corresponding author): Eren ÖZDAMAR, erenozdamar@fernas.com.tr 


\section{GíRiș}

Zemin, kayaların fiziksel ve kimyasal olaylarla parçalanarak ufalanması sonucu oluşan, kazma kürekle bir yerden diğerine taşınabilen malzemelerdir [1]. Mühendislik biliminde zemin olarak isimlendirilen değişik boyutlu malzemeler, doğada sert ve masif kaya kütlelerinin fiziksel ve kimyasal yollarla ayrışması sonucu oluşurlar [2].

Zeminler, baraj ve karayolu dolguları gibi çoğu alanlarda malzeme olarak kullanılmaktadır. Zeminlerin dayanımı, rijitliği, stabilitesi (duraylılığ1, dengesi), erozyona ve sulamaya karşı direnci, söz konusu zemin üzerinde yapılacak deneyler ile belirlenebilmektedir. Yol kaplamalarının altında kullanılan zeminler, dolgular ve diğer toprak dolgu yapılarında zeminler inşaat süresince kompaksiyon ve karışım oranları açısından deneylerle sürekli olarak kontrol edilmelidir. Deneylerin yapılmasında ve sonuçlarının değerlendirilmesinde evrensel olarak yaygın sistemler kullanılır [2]. Yol, hava alan1, toprak baraj, toprak dolgu inşaatlarında, zemin belli bir kalınlıkta serilerek, belli bir su muhtevasında, uygun bir sıkıştırma aracı ile sıkıştırılır. Kompaksiyonla, zeminin sabit, hareketli, dinamik yükler altında yapacağı oturmalar azalır. Kompaksiyon; zemin tabaka serilerek, silindirleme, vibrasyon (titreşim) uygulama, tokmaklama gibi işlemlerle yapılmaktadır. $\mathrm{Bu}$ işlemlerle, zemin taneleri daha az boşluklu yerleşerek, zeminin boşluk oranı azaltılır. Yol, hava alanı, toprak baraj, toprak dolgu inşaatlarında, zemin belli bir kalınlıkta serilerek, belli bir su muhtevasında, uygun bir sıkıştırma aracı ile sıkıştırılır [3].

$\mathrm{Bu}$ çalışmada, (Çorum-Merzifon) AyrımıMecitözü- (Amasya-Turhal) Ayrımı 0+000$61+841,27 \mathrm{~km}$ arası bölünmüş yol yapımı işi dahilinde, Karayolu temel/alttemel zemin uygulamaları incelenmiştir. Zemin analizleri neticesinde belirlenen zayıf zemin sonucunda yapılması gereken yarma dolgu ve iyileştirme kısımlarıyla devam edilmiştir. Km: 11+500-23+600 arasında dolgu ve terasman kotunda optimum zemin stabilizasyonu değerlerine ulaşılmıştır. Daha sonra çalışılan program dahilinde, agrega deneyleri, üstyapı dizaynı olan Plant Mix Alt Temel (PMAT) ve Plent Mix Temel (PMT) belirlenmiş ve yapılan çalışmalar sonucunda Km: $17+280-19+600$ arasında optimum zemine ulaşılmıştır.

\section{MATERYAL VE METOT}

\subsection{Materyal}

Bu çalışmada, Yedigöze İnş. San. Oto. İç ve Dış Tic. Ltd. Şti. ve Sigma İnş. ve Tur. İşl. Tic. A.Ş. İş Ortaklığı'nın ana yüklenici, Fernas Şirketler Grubu bünyesindeki Simtek End. Tes. ve Tic. A.Ş.'nin alt yüklenici olarak yürüttüğü (Çorum-Merzifon) Ayrımı -Mecitözü- (Amasya-Turhal) Ayrımı 0+000-61+841,27 km arası bölünmüş yol yapımı işi dahilinde yürütülmüştür. Yapımına 2017 yılında başlanmış ve halen devam etmekte olan proje çalışmaları kapsamında Karayolu temel/alttemel zemin uygulamaları üzerine yoğunlaşılmıştır.

Çalışma alanının, projenin başlangıç yeri olan KM: 0+000 noktasının Çorum'a olan uzaklığg 17, bitiş kısmı olan KM: 61+847'nin Amasya'ya olan uzaklığı ise 13 kilometre'dir. Mecitözü İlçesi'nin batısında Çorum il merkezi, doğusunda Amasya İli, güneyinde Ortaköy İlçesi ve kuzeyinde ise Amasya'nın Merzifon ilçesi yer almaktadır. İlçe genel olarak doğu-batı doğrultusunda uzanan hafif dalgalı bir sahada yer almaktadır. Çalışma sahası kahverengi toprakların yayılış alanı olmakla birlikte, akarsuların çevresinde alüvyal topraklara, yamaçlarda ise kolüvyal topraklara rastlanmaktadır.

\subsection{Metot}

$\mathrm{Bu}$ çalışmada KTŞ baz alınarak; sırasıyla zemin analizleri ve deneylerinin yapılması (elek analizi, likit limit-plastite indeksi, standart ve modifiye proktor, cbr, şişme) yarma-dolgu-iyileştirme çalışmaları, reglaj (sıfırlama), agrega deneyleri, PMAT (plent mix alttemel) ve PMT (plent mix temel) bölümleri üzerinde durulmuştur. İlk olarak zemin analizleri için km:23+600'den $40 \mathrm{~kg}$ numune alınarak laboratuvar deneyleri yapılmıştır. Alınan sonuçlara göre zayıf zemin tespit edilerek kontrollü dolgu şeklinde farklı bölgelerden filtre, taş ve ariyet (kum-çakıl) malzemesi getirilerek zemin iyileştirilmesi yapılmıştır. 
Kompaksiyon yöntemi kullanılarak; buldozer, greyder ve silindir vasitasiyla, proktor deneyi sonucu bulunan optimum su verilerek sermesıkıştırma işlemleri yapılmıştır. Reglaj çalışmaları tamamlanan bölümlere kum konisi deneyi ve kamyon testi yapılarak KTŞ’ye göre, dolguterasman kotunda \%97-100 arasında sıkışma sağlanıp sağlanamadığı test edilmiştir. YedigözeSigma İnş. A.Ş [4] bünyesindeki laboratuvarda elek analizi, Los Angeles aşınma ve metilen mavisi deneyleri yapılarak agrega davranışı izlenmiştir. Alttemel/temel çalışmaları için agrega dizaynları belirlenmiştir. $\mathrm{Bu}$ oranlar sabit tutularak ve optimum su muhtevası gözetilerek serme-sıkıştırma işlemleri gerçekleştirilmiştir. Sağlamlık kontrolü için yapılan kum konisi deneyleri sonucunda, Km: 11+500-23+600 arasında \%98,4-100 sıkışma ile dolgu-terasman kotunda, km: 17+280-19+600 arasında \%98,0-99,8 sıkışma ile PMAT kotunda, $\mathrm{km}: 17+280-19+600$ arasında \%100 sıkışma ile PMT kotunda, (KTŞ'ye göre) elde edilen veriler neticesinde çalışmalar tamamlanarak, optimum zemin stabilizasyonu sağlanmıştır.

\section{BULGULAR}

Zemin analizleri için $\mathrm{Km}: 23+600$ noktasından alınan numuneye yapılan elek analizi sonucu A-7-6 killi topraklar olduğu belirlenmiştir. Buna göre; likit limit (LL) 42, plastisite indeksi (PI)20, Kaliforniya taşıma gücü (CBR) 2,6, şişme \%5,37, maksimum kuru birim hacim ağırlı $1,718 \mathrm{~g} / \mathrm{cm}^{3}$ ve optimum su muhtevası \%15,09 olarak bulunmuştur (Şekil 1).

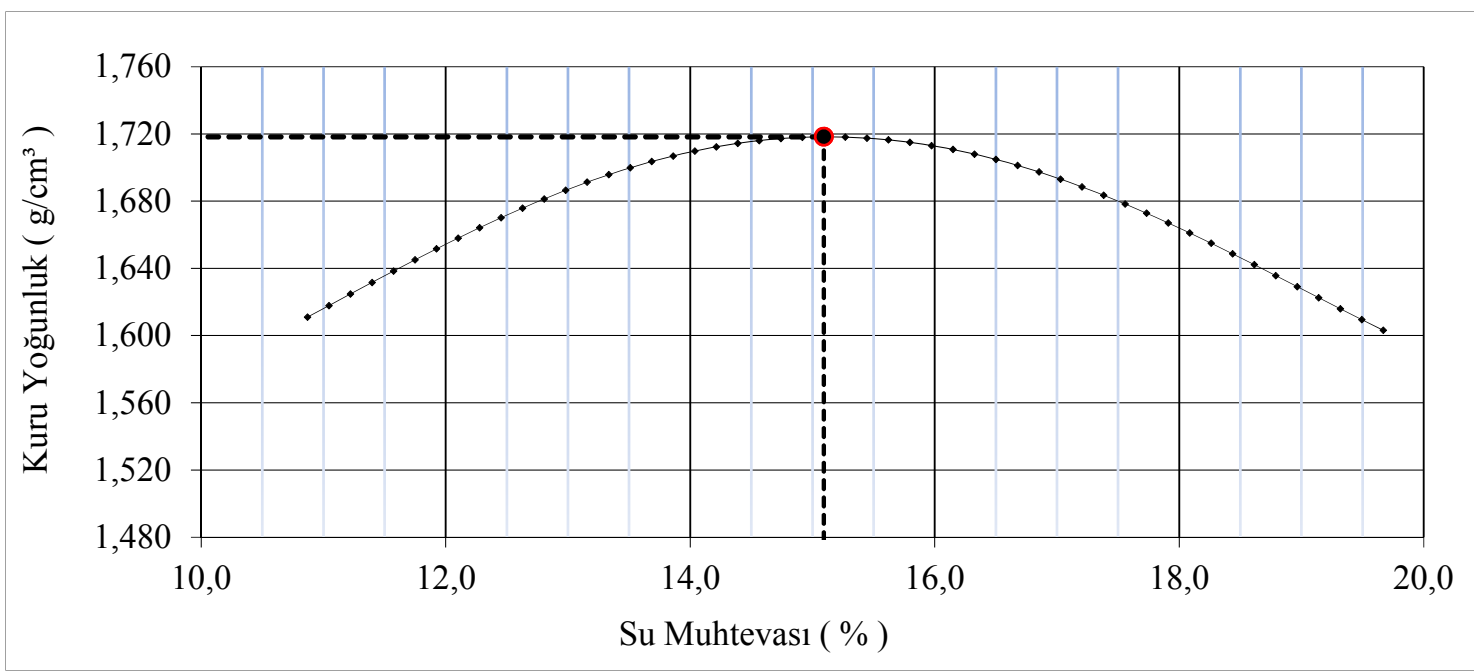

Şekil 1. Km: 23+600, kompaksiyon testi; kuru yoğunluk ve su muhtevası grafiği

$\mathrm{Bu}$ çalışma KTŞ [5] gözetilerek yürütülmüştür. Zemin iyileştirme çalışmaları için proje ilerleyişine göre, Km: $11+820$ kesiminde açılan araştırma çukurunda yapılan elek analizleri sonucunda, A-2-7 siltli veya killi çakıl ve kuma rastlanmıştır. Çizelge 1'e göre uygun nitelikli kazı malzemesi olsa da, kontrol şefi tarafindan bölgesel olarak zayıf zeminler olduğu gerekçesiyle dişarıya aktarılmıştır. Doğal su içeriği \%15,2 olduğundan su alması zeminin taşıma gücü sebebiyle düşmektedir. Km:
$11+530-12+180$ arasında yol platformu yol platformu taban alanındaki bitki, toprak, ağaç kökleri, vs sıyırılarak $75 \mathrm{~cm}$ yarma (zayıf zemin kazısı) ile oluşturulmuştur. $\mathrm{Bu}$ verilere göre $\mathrm{Km}$ : $11+530-12+180$ arasında zayıf zemin kazısı yapılan bölüme $75 \mathrm{~cm}$ dona hassas olmayan malzeme niteliğinde koruyucu tabaka getirilmiştir. Maksimum kuru birim hacim ağırlığ 2,018 g/ $\mathrm{cm}^{3}$, optimum su muhvetası \%9,29'dur. Yapılan diğer laboratuvar çalışmaları sonucu Çizelge 2'de gösterilmiştir. 
Çizelge 1. Uygun nitelikli kazı malzemesi [5]

\begin{tabular}{|l|c|c|}
\hline Deney & $\begin{array}{c}\text { Şartname } \\
\text { Limiti }\end{array}$ & Km:11+820 Deney Sonuçları \\
\hline Likit Limit, (LL) & $\leq 60$ & 48 \\
\hline Plastite İndeksi, (PI) & $\leq 35$ & 28 \\
\hline $\begin{array}{l}\text { Maksimum Kuru Birim Hacim Ağırlık } \\
\text { (Standart Proktor)* }\end{array}$ & $\geq 1,450 \mathrm{t} / \mathrm{m}^{3}$ & 1,475 \\
\hline$*$ PI $\leq 6$ VE CBR $>10$ olan doğal cüruf ve tüflerde bu şart aranmayacaktır. \\
\hline
\end{tabular}

Çizelge 2. Dona hassas olmayan malzemelerin özellikleri [5]

\begin{tabular}{|l|c|c|}
\hline Deney & $\begin{array}{c}\text { Şartname } \\
\text { Limiti }\end{array}$ & $\begin{array}{c}\text { Mecitözü Ariyet Ocağı (A.C.-1), } \\
\text { Deney Sonuçları }\end{array}$ \\
\hline $0,075 \mathrm{~mm}$ Elekten Geçen, \% & $\leq 12$ & 12,1 \\
\hline Likit Limit, (LL) & $\leq 25$ & $\mathrm{NP}$ \\
\hline Plastite İndeksi, (PI) & $\leq 6$ & $\mathrm{NP}$ \\
\hline Kaba Agregada Su Absorbsiyonu, (\%) & $\leq 3$ & 0,58 \\
\hline
\end{tabular}

Malzeme 20-30 cm kalınlığında, yatay tabakalar halinde, çalışma ağırlığı 20,021 kg olan $6-8 \mathrm{~km} / \mathrm{saat}$ hızında olan paletli dozer ile serilmiş, $11.000 \mathrm{~kg}$, statik çizgisel yükü $30 \mathrm{~kg} / \mathrm{cm}$ 'den fazla olan, iki frekanslı vibrasyon sistemli düz bandajlı silindirle sıkıştırılmıştır. Sıkıştırma sırasında, malzemenin su içeriği, proktor (modifiye) metodu ile bulunan Wopt \pm 2 değerleri arasında kalmasına dikkat edilmiştir

Arazide proktor deneylerinden elden edilen kuru birim hacim ağırlık ve optimum su muhtevasına göre serilen malzemeye yapılan deneme çalışmaları sonucu Şekil 2'de gösterildiği gibi 3 ile 5 pass arasında çalışıldığında, istenilen düzeyde sıkışma elde edilmiştir. Buna göre sıkıştırma işlemi, KTŞ dolgularda sıkışma kriterleri de baz alınarak, ortalama 3-5 pass (ileri-geri) atılarak yapılmıştır. Zemin iyileştirme çalışmaları projenin ilerleyişi gözetilerek Km: $11+500$ ile Km: $23+600$ arasında devam ederek tamamlanmıştır.

Terasman kotunda Km: 11+560-19+600 arasinda muhtelif yerlerde yapılan kum konisi deneyi sonucunda, bu aralığın tamamında \%100 sıkışma değerleri elde edilmiştir. KTŞ'ye göre \%100 olması gereken sıkışma değerine ulaşıldığı için, optimum zemin değerleri elde edilmiştir. Dolgu kotunda Km: $16+400-23+500$ arasinda muhtelif yerlerde yapılan kum konisi deneyi sonucunda \%98,4 ile 99,1 arasında sıkışma değerleri elde edilmiştir. KTŞ'ye göre en az \%95 olması gereken sıkışma değerinden büyük olduğu için, optimum zemin değerleri elde edilmiştir.

Plent Mix Alttemel (PMAT) ve Plent Mix Temel (PMT) tabakası oluşturulmadan önce agrega deneyleri yapılmıştır. Los Angeles aşınma \%19, Metilen mavisi (MB) 1,0-2,0 $\mathrm{ml} / \mathrm{g}$ arasında bulunmuştur. Proje için gerekli alttemel/temel dizaynları oluşturulmuştur. Buna göre laboratuvarımızda yapılan çalışmalar neticesinde (Karışım oranları-karışım gradasyonu-tolerans limitleri); Km: 2+640'da bulunan Elvançelebi taş ocağında üretilen $(38-19 \mathrm{~mm}),(19-12 \mathrm{~mm})$, $(12-5 \mathrm{~mm})$ ve $(5-0 \mathrm{~mm})$ dane boyutu grubu agregalardan 15 adet şantiye elek analizi ortalamaları dizayna esas alınmıştır. KTŞ'ne göre; PMAT Tip-B [5] gradasyon limitleri içinde kalmak koşuluyla, PMAT için; \%37 (38-19 mm), \%14 (19-12 mm), \%12 (12-5 mm), \%37 (5-0 mm) oran1 belirlenmiştir. 


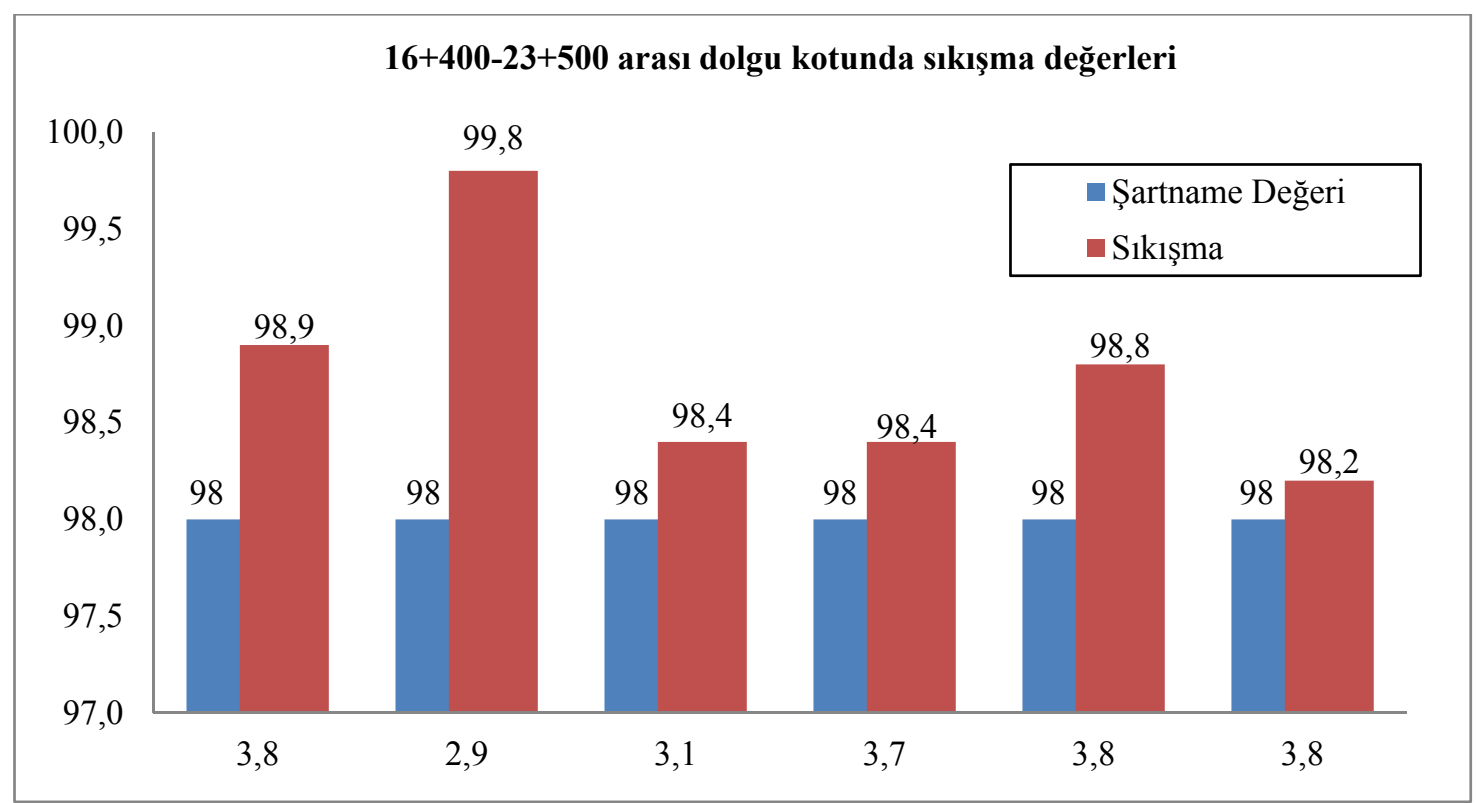

Şekil 2. Km: 16+400-23+500 arası dolgu sıkışma, grafik gösterimi (yatay eksen: arazi su içeriği, (\%), düşey eksen sıkışma değerleri, (\%) verilmiştir)

Sıkıştırma, çalışma ağırlığı en az 11.000 kg statik çizgisel yükü $30 \mathrm{~kg} / \mathrm{cm}$ 'den büyük, iki frekanslı vibrasyon sistemli düz bandajlı silindir ve lastik başına düşen yükü 3.500 kg'dan az olmayan lastik tekerlekli $9.000 \mathrm{~kg}$ vabil silindirle yapılmıştır. Kullanılan malzeme ve serilen tabaka kalınlığına uygun sıkıştırma tekniği, 4-5 pass arasında deneme çalışmaları yapılarak bulunmuştur (Şekil 3).

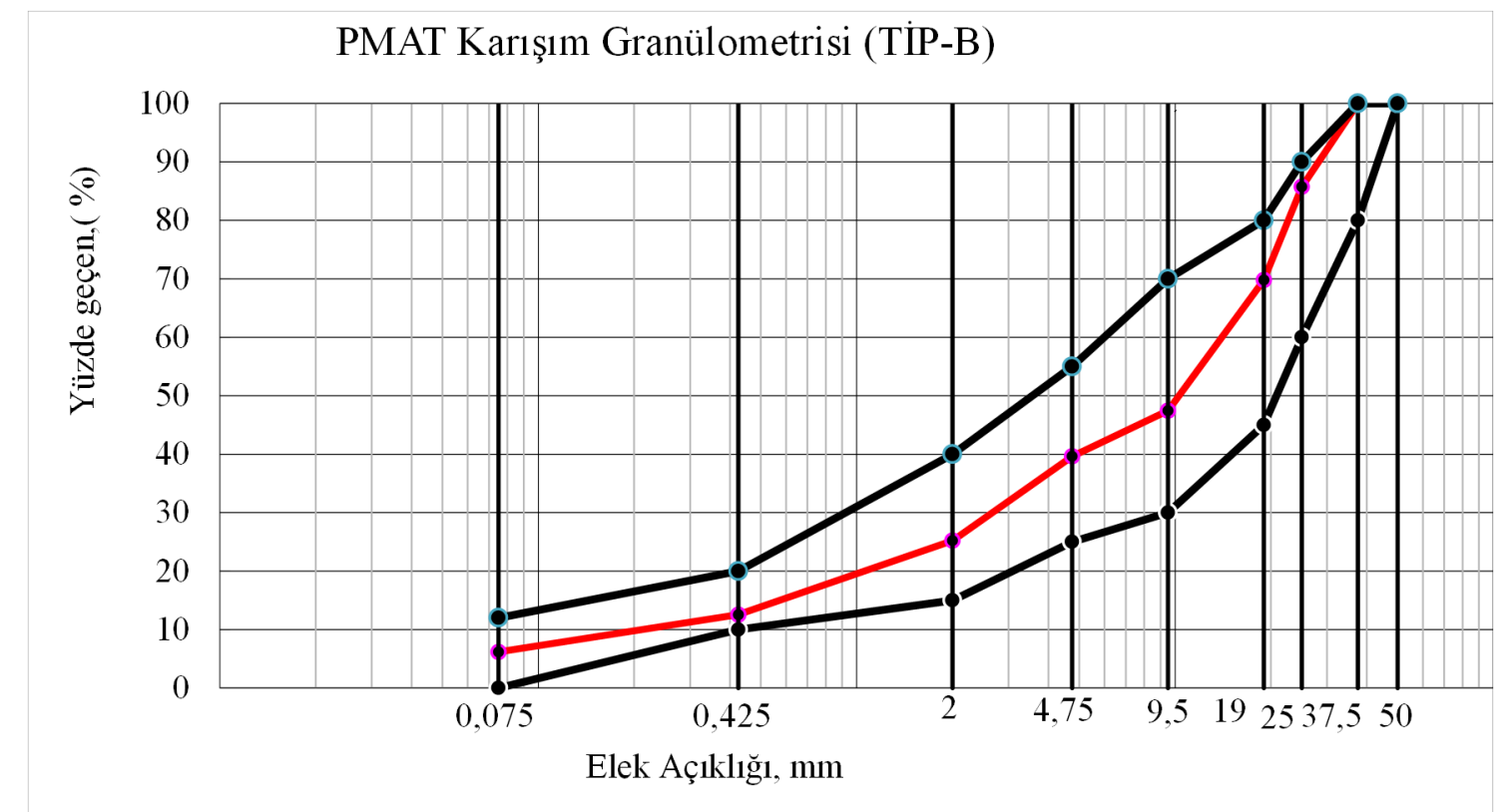

Şekil 3. PMAT karışım granülometrisi (TİP-B) 


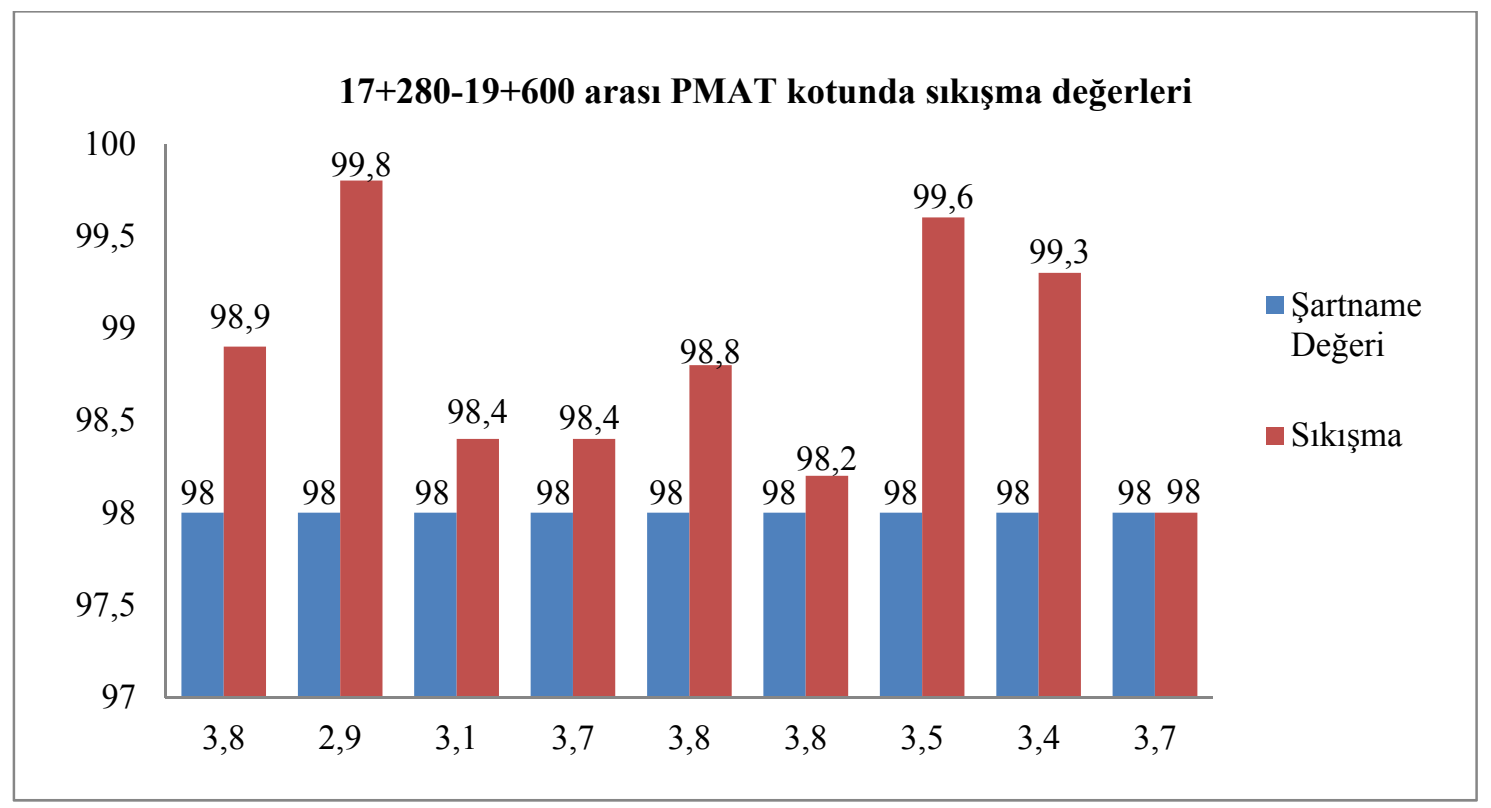

Şekil 4. Km: 17+280-19+600 arası dolgu sıkışma, grafik gösterimi (yatay eksen: arazi su içeriği (\%), düşey eksen sıkışma değerleri (\%), verilmiştir)

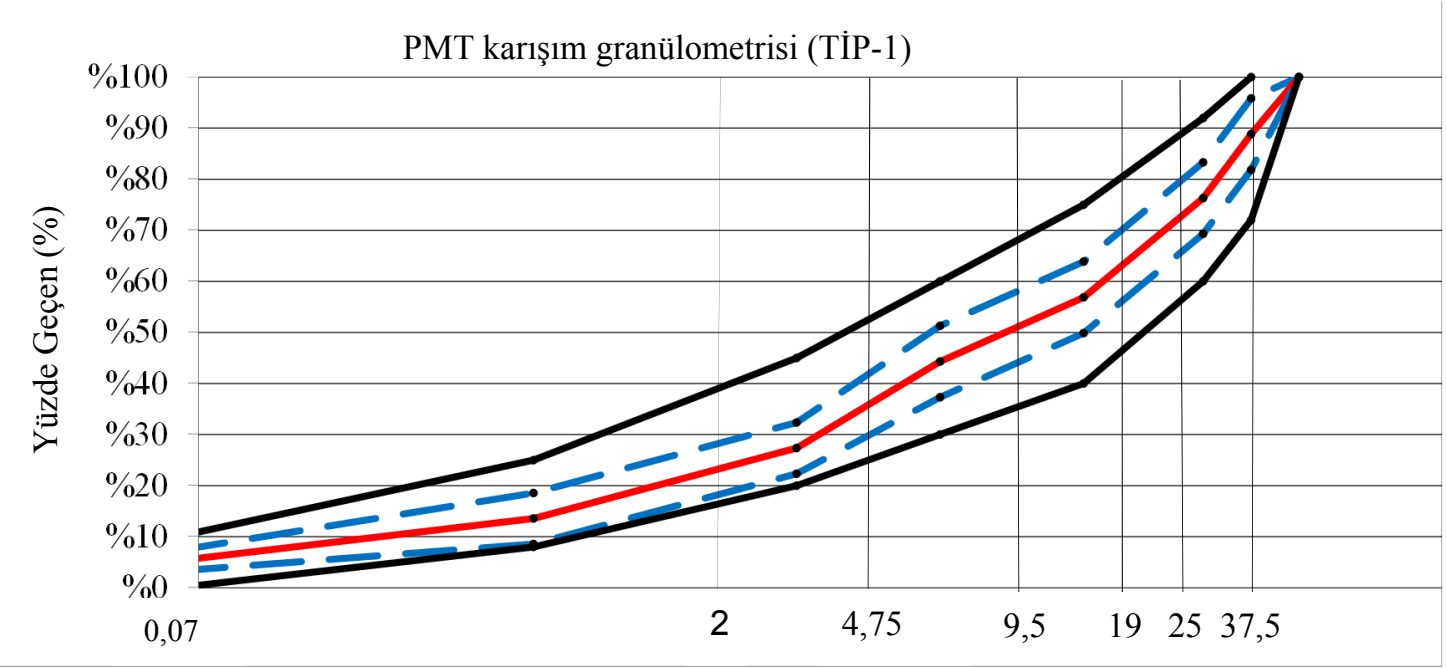

Şekil 5. PMT karışım granülometrisi (TIP-1)

\section{SONUÇLAR}

Yapılan kum konisi deneyleri sonucunda yol zemininde \%98-100 varan sıkışmalar gözlenmiştir. $\mathrm{Km}: \quad 11+500-23+600$ arasinda yapılan zemin analizleri neticesinde tamamına yakını (KTŞ'ye göre) zayıf zemin olarak tespit edilmiştir. $\mathrm{Bu}$ verilere göre projenin devaminda Km: $61+841$ 'e kadar güzergah boyunca aynı formasyon (kuvaterner yaşlı alüvyon) devam ettiği için zayıf zeminlere rastlanacaktır. Öyle ki daha önceden yapilan Km: 38+600'deki zemin analizleri sonucunda zayıf zeminin tespit edilmesi, öngörüleri doğrulamaktadır. 
$\mathrm{Bu}$ çalışmanın ana teması olan, Karayolu temel/alttemel zemin uygulamaları kapsamında, optimum zemin değerlerine; kum konisi deneyi sonucunda, Km: $11+500-23+600$ arasinda \%98,4100 sıkışma ile dolgu-terasman kotunda ulaşılmıştır. Terasman seviyesinde hazırlanmış olan $\mathrm{Km}: \quad 12+180-12+220$ arasinda, (17.5.2019 tarihinde) hızı $6 \mathrm{~km} / \mathrm{saat}$, ağırlığ 36 ton olan 10 tekerli kamyon yolun sağ platformun sağ taraf, eksen ve sol tarafindan geçecek şekilde hareket ettirilerek "Doğrulama (kamyon) Testi" yapılmıştır. Yapilan test sonucunda lokal olarak esneme, defleksiyon, çökme vb. unsurlar gözlenmiştir. Maksimum kuru birim ağırlık 2,018 $\mathrm{g} / \mathrm{cm}^{3}$, optimum su muhvetası \%9,29 olan dona hassas olmayan nitelikteki malzeme sökülmüştür. Bir süre havalandirilarak kurutulduktan sonra tekrar iyileştirme yapılarak optimum verilere ulaşılmıştır.

Dona hassas olmayan malzeme niteliğindeki, maksimum kuru birim ağırlık 2,018-2,172 g/ $\mathrm{cm}^{3}$, optimum su muhtevası \%7,00-9,29 arasinda değerlere sahip ariyet malzemesi temini konusunda birkaç hafta aksaklıklar yaşanmıştır. Aynı zamanda ariyet ocağında, özellikle tabana inildikçe (basınçlı akiferlerden su çıkışları nedeniyle) optimum su muhtevasındaki değişimlerden dolayı yapılan iyileştirme çalışmalarında sorunlar gözlenmiştir.

Kompaksiyon yöntemiyle yapılan sıkıştırma işleminde, yapılan arazi kuru birim ağırlık tayini, deneme sıkıştırmaları ve gözlemler sonucu (11.000 $\mathrm{kg}$, statik çizgisel yükü $30 \mathrm{~kg} / \mathrm{cm}$ 'den fazla olan, iki frekanslı vibrasyon sistemli düz bandajlı silindir ve lastik başına düşen yükü 3.500 kg'dan az olmayan lastik tekerlekli $9.000 \mathrm{~kg}$ vabil silindirle) 3-5 pass arasında sıkışma değerleri elde edilmiştir.

Kuvaterner yaşlı alüvyonlar güzergah boyunca devam ettiği için, araştırma raporlarına ve elde edilen bulgulara göre zayıf zeminler mevcuttur. Yarma yapılan bölümlerden çıkan malzemeler KTŞ'ye göre uygun nitelikli kazı malzemesi özelliğini taşımadığı görülmüştür.

Mekanik kısım olan PMAT ve PMT bölümlerine başlanmadan önce yapılan hazırlık çalışmalarında MB 2,5-3,5 arasında çıkmasından dolayı, konkasör tesisindeki taş-toprak ayrımını yapan bypas eleği
(24 mm) büyültülerek (38 mm) kirlilik oranı MB 1,0-2,0 değerleri arasına çekilmiştir. Mekanik kısımda çalışılmadan önce MB kirlilik oranı ayarlanmalıdır.

\section{KAYNAKLAR}

1. Toprak ve Stabilizasyon Laboratuvarı El Kitab1, Ocak, 1989. Teknik Araştırma Dairesi Başkanlığı Üstyapı Şubesi Müdürlüğü, 1-3.

2. Kılıç, A. M., 2012. Zemin Mekaniği, Ders Notu, Adana.

3. Uzuner, B., 2000. Temel Mühendisliğine Giriş. Derya Kitabevi, Trabzon, 205.

4. Yedigöze İnş. San. Oto. İç ve Dış Tic. Ltd. Şti.+Sigma İnş. ve Tur. İşl. Tic. A.Ş. İş Ortaklığı'nın ana yüklenici, Fernas Şirketler Grubu bünyesindeki Simtek End. Tes. ve Tic. A.Ş.'nin alt yüklenici, Laboratuvar verileri, deney formatlar1, 2018-2019. Amasya.

5. Karayolları Teknik Şartnamesi. 2013, KGM yayın1, Ankara. Kısım, 203/1, 206/1-2, 206/9, 401/1-6, 402/2-3, 402/7-8, 402/10. 
